\title{
La interpretación de Emmanuel Levinas de Ideas I de Husserl
}

Recibido: julio 25 de 2017 | Aceptado: febrero 23 de 2018

DOI: 10.17230/co-herencia.15.29.5

\section{M. ${ }^{\text {a Carmen López Sáenz }}{ }^{*}$ \\ clopez@fsof.uned.es}

Resumen Este artículo describe en un primer momento la herencia que Levinas recibe de Bergson y de la fenomenología de Husserl. Luego, pone el acento en la profundidad con la que captó, desde los años 20, el significado del idealismo trascendental de la obra Ideas I (1913) de Husserl. Ello se suma a su re(con)ducción a lo trascendental, entendida como el sentido de la existencia ignorado por la ontología naturalista. La interpretación levinasiana de la controvertida "reducción" marcará tempranamente tanto sus diferencias con Heidegger como su adhesión a la fenomenología genética, especialmente a la intencionalidad horizóntica y no representativa. En ese orden de ideas, analizaremos la continuación levinasiana de esta fenomenología y su conclusión en la irreductibilidad de la responsabilidad ética.

\section{Palabras clave:}

Fenomenología, existencia, intencionalidad, intuición, reducción.

\section{The interpretation of Emmanuel Levinas of Ideas I by Husserl}

\begin{abstract}
This article starts by describing Levinas' legacy both from Bergson and from Husserl's phenomenology. Next, it explores how Levinas deeply understood, as early as the 1920s, the meaning of Husserl's transcendental idealism of Ideas I (1913). He adheres to Husserl's re(con)duction to the transcendental -understood by Levinas as the sense of existence which is overlooked by the naturalist ontology-. The Levinasian interpretation of the controversial 'reduction' marked, at an early stage, his differences with Heidegger and his adhesion to the genetic phenomenology, particularly to the horizontal and non-representational intentionality. Finally, the Levinasian continuation of this phenomenology as well as its conclusion, that is, the irreducibility of ethical responsibility, will be analysed.
\end{abstract}

\section{Keywords:}

Phenomenology, existence, intentionality, intuition, reduction.
Este trabajo se desarrolló en el marco del proyecto de investigación subvencionado, MINECO, FFI2015-63794-P. Agradezco las precisas sugerencias de los evaluadores de este artículo.

${ }^{* *}$ Doctora en Filosofía. Catedrática de la Universidad Nacional de Educación a Distancia (UNED), España. ORCID ID: 0000-00034207-0579 


\section{De la intuición a la intencionalidad}

Sin duda la obra temprana de Emmanuel Levinas fue decisiva para la recepción de la fenomenología en Francia, la cual se caracteriza, desde entonces, por la confianza en las potencialidades de la intencionalidad de la conciencia, una confianza que permitirá dar cumplimiento al proyecto bergsoniano de una filosofía concreta. Esta se convierte en Levinas en una fenomenología de la existencia que comienza con la intuición fenomenológica del ser, la cual constituye -como la intuición bergsoniana- un contrapunto a la aproximación metafísica a la existencia, puesto que la intuición es un acto que nos pone en contacto con el ser. Su fenomenología desembocará, como es sabido, en la ética.

En este estudio no nos centraremos en ella, sino en los comienzos de su filosofía, especialmente en su interpretación de la fenomenología en clave ontológica y en su práctica de la misma como "una invitación al trabajo" (Levinas, 1929, p. 46). ${ }^{\text {S Se encuentra }}$ con esta corriente tempranamente, en 1923, en el Instituto de Filosofía de Estrasburgo, a través de Pradines, Blondel, etcétera; "en cambio, he subrayado poco la importancia -para mí capital- de la referencia a Bergson, como fondo de la enseñanza de aquellos maestros" (Levinas, 1991, p. 253). Es consciente de que ya apenas se le cita, de que se ha olvidado que en su duración está ya presente la tematización heideggeriana de la diferencia ontológica y que la intuición es la vivencia de esa duración como dia-cronía, la vivencia de lo espiritual, que es irreducible a mero saber. Viellard-Baron ve, en efecto, que la esencia de la filosofía levinasiana -el rostro del otro- se da en una intuición que impulsa al pensamiento y a la que siempre se vuelve (2010, p. 460). Levinas considera la intuición bergsoniana de la duración como una rehabilitación de la vida interior y del espíritu en un sentido muy diferente del hegeliano, dado que Bergson prioriza la acción y la entiende como punto de encuentro entre la vida y la materia. Por ello, su duración influyó en la concepción levinasiana de la temporalidad originaria como diacronía, cuyo carácter no

1 El idealismo fenomenológico es interpretado por Levinas como "invitación a la investigación filosófica" y no como "una tesis que la resuma" (1949, p. 48). Si no se indica lo contrario, todas las traducciones son de la autora. 
intencional trascendía la concepción husserliana de la conciencia interna del tiempo. A pesar de ello, Levinas echa en falta en la duración esa divergencia originaria que denomina "lo inmemorial". Su crítica se debe a que no comprendió "el sentido profundo del bergsonismo, que es ser un espiritualismo epistemológico" (ViellardBaron, 2010, p. 478) en el que el saber hacer, la intuición y la acción permanecen unidos por motivos fundamentalmente pragmáticos.

En Estrasburgo, gracias a Pfeiffer profundizó en las Investigaciones lógicas. Más adelante, traducirían juntos las Meditaciones cartesianas. Su reseña de 1929, "Sur les Ideen de M. E. Husserl", cifra lo fundamental de Ideas I en su superación del dualismo escolástico entre el sujeto y el objeto mediante la intuición directa de lo real, que reconcilia lo mejor del idealismo y del realismo; va más allá de la oposición entre la espontaneidad del espíritu y la percepción sensible, sin renunciar a la profundización en la verdad del mundo de la vida que habitamos. Esta verdad depende del objeto, pero no desemboca en una metafísica realista, porque la intencionalidad esencial hacia él, previa a la tematización de su existencia o no existencia, es la que funda la verdad de las intenciones del pensamiento, y esta verdad se origina en la intuición, fenomenológicamente entendida como acto de la conciencia que presenta al objeto y que no es únicamente un modo de conocimiento, sino "el fenómeno primitivo que hace posible la verdad misma” (Levinas, 1930, p. 19). Dicha verdad es la otra cara de la evidencia intuitiva: "la noción de la razón se define por ella" (Levinas, 1949, p. 31), y la intención es una evidencia que se busca. En efecto, Husserl ve en la intuición fenomenológica la racionalidad de la razón, el principio de todos los principios, un principio que no es comprensible empíricamente (Husserl, 1913, p. 21), pero tampoco queda recluido en la conciencia, sino que adquiere sentido cuando se describen sus estructuras. La intuición fenomenológica no es solo un método para ello; nos brinda un conocimiento que nos involucra y evita nuestra conversión en objetos. Por eso, Levinas la considera más valiosa incluso que la intuición bergsoniana para expresar la vida del espíritu dotado de pensamiento (1949, p. 55).

Esto es especialmente evidente en la intuición eidética (Wessenschau) que, como la intuición sensible, nos da su objeto (en este caso, la esencia) originariamente; es decir, en ambas intuiciones la conciencia 
se encuentra directamente ante el ser. La fenomenología dirige la mirada a la conciencia a la que se ofrecen las esencias y, por ello, se considera ciencia eidética de la misma que, en la interpretación ontológica levinasiana, desvela el proceso por el que el ego llega a las cosas mismas, "a lo que hace el ser del objeto" (Levinas, 1930, p. 97). Esto es posible gracias a la esencia del ser de la conciencia, a la intencionalidad, sin mediación de representación: "la fenomenología es una destrucción de la representación y del objeto teórico" (Levinas, 1949, p. 160). Una vez eliminado el representacionismo, Husserl eleva la conciencia a un acontecimiento que despliega "la energía o essance", "el acto o el acontecimiento o el proceso de l'esse" (Levinas, 1991, p. 82). ${ }^{2}$ En efecto, la esencia fenomenológica no es una representación del objeto en la conciencia, sino que pertenece a su intendere. Su modo de existir nos revela otra dimensión del ser: la idealidad.

Las esencias se aprehenden partiendo de las vivencias individuales, pero ni construyendo con ellas un objeto mental ni inductivamente, sino por ideación, es decir, llevando a la unidad de la idea la multiplicidad de los actos perceptivos, imaginativos, etcétera. Por ideación se intuye la esencia "cosa" como "sujeto de determinaciones noemáticas tomadas en su universalidad” (Husserl, 1913, p. 345), pero reconociendo el eidos en la realidad vivida; es decir, la unidad de las apariciones viene de las esencias que vertebran hechos, pero no están sometidas a la existencia real, sino que son posibilidades puras. En otras palabras, la ideación da la esencia originariamente, sin inferirla de las experiencias actuales: "Las puras verdades esenciales no contienen la menor afirmación sobre hechos, por lo que tampoco cabe concluir de ellas solas la más insignificante verdad de hecho" (Husserl, 1913, pp. 16-17).

A diferencia de Husserl, Bergson pensaba que no era posible aprehender la multiplicidad de la vida consciente mediante las esencias, porque las consideraba construcciones intelectuales que detenían la duración y la libertad de la vida espiritual. Ciertamente este no es el sentido de las esencias fenomenológicas: no son conceptos

2 El filósofo lituano reconoce que su interpretación de la intuición de Husserl estuvo influenciada por Sein und Zeit y, por ello, presentaba al padre de la fenomenología como si hubiera sido consciente del problema ontológico del ser (Levinas, 1981, p. 36). 
impuestos a las cosas, sino condiciones de la existencia y el "estilo necesario y constante" (Levinas, 1929, p. 47) del objeto individual. El pensador lituano descubrirá, además, en la fenomenología genética esencias materiales y esencias inexactas dinámicas que tipifican nuestra experiencia sin imponerle teorías abstractas. Valora positivamente el hecho de que la fenomenología no se conforme con describir las esencias, sino que se pregunte por sus modos de existencia: las esencias existen primero como intencionalidad, en cuanto donación de sentido; después, como ese modo de ser del mundo referido a la conciencia por el que el sujeto se presenta junto a las cosas trascendentes a ella. Así se comprende que el en-sí pueda devenir subjetivo y que el sujeto sea capaz de abrirse a la alteridad.

Gracias a su intencionalidad, la intuición fenomenológica, a diferencia de la bergsoniana, es correlación con la duración y no coincidencia plena con ella. Además, la intuitividad de la razón y la ideación husserlianas superan el antagonismo bergsoniano del intelecto y la intuición. Sin embargo, la intuición de Husserl no es, como la de Bergson, un acto en el que se comprometen todas las fuerzas vitales, sino una reflexión que no aclara adecuadamente la naturaleza de la vida trascendental y su relación con la existencia concreta. Levinas intenta por su cuenta esa clarificación y, por ello, comprende la intuición como un modo de vida en el que el objeto mentado no solo es significado, sino originariamente dado. Debido a esto último, la conciencia no puede ser la garantía de su verdad, sino que ella misma depende del modo de existir intencional. Este es el fenómeno originario de la verdad. Desde él, puede comprenderse la adecuación a la que se refiere Husserl, que no es la de las representaciones subjetivas con la cosa, sino la correspondencia entre lo mentado y la intuición del objeto. No hay aquí consciencialismo alguno, dado que el objeto está presente tanto en la mención como en la intuición.

"Analizar las intencionalidades que constituyen un objeto determinado u otro, es hacer fenomenología" (Levinas, 1931, p. 101), bien entendido que la "constitución" no es la determinación puramente subjetiva del conocimiento, sino el descubrimiento de las estructuras constitutivas de las cosas mismas. Este es el sentido del idealismo trascendental fenomenológico tan enfrentado al naturalismo, que 
ignora las esencias y el espíritu, como opuesto al subjetivismo trascendental, que todo lo reduce a una construcción del sujeto. La actividad trascendental, la constitución del sentido recibe con la fenomenología una nueva orientación que no es ni la del constructivismo ni la del sensualismo, sino la simultaneidad de la espontaneidad y de la pertenencia, pues "el mundo no es solo constituido, sino también constituyente. El sujeto no es ya puro sujeto; el objeto no es ya puro objeto. El fenómeno es a la vez lo que se revela y lo que revela, ser y acceso al ser" (Levinas, 1949, pp. 184-185).

En sus últimas producciones, ${ }^{3}$ el filósofo lituano continúa pensando que el principio esencial de la fenomenología es la intencionalidad, aunque se muestra más crítico con ella por considerar que todavía está presa en el horizonte del saber, pues, aunque contiene la distinción entre el objeto de la representación intencional y el acto, aquel sigue siendo interior al pensamiento. Levinas defenderá otra intencionalidad capaz de reconocer la trascendencia radical de la relación ética, porque permanece abierta a una trascendencia diferente del hors-de-soi (1991, p. 81). Tal concepción de la intencionalidad asegura la posibilidad de la verdad sin mediación de representación, como apertura a un nuevo tipo de acontecimiento profundo cuya intención viene de nuestra relación con las cosas movida por el deseo. La ejemplifica con la intención de amar, que pertenece a la existencia del mundo y pone de manifiesto que "no es un medio -indiferente'- de pura representación" (1949, p. 75). El deseo como la voluntad no son intenciones que constituyan el mundo, pero tampoco se reducen a meros elementos de la conciencia pura.

El filósofo lituano valora el hecho de que la intencionalidad no solo correlacione la sensación con lo sentido, sino que, además, subraye la idealidad de este último y la extienda a los sentimientos entendidos como "nuestra trascendencia en relación con nosotros

3 C. Pagés (2010, pp. 265, 282) ha declarado que Levinas lee la intencionalidad husserliana de dos modos divergentes: como trascendencia en el sentido de apertura, y como representación que subyace a la intencionalidad de lo mismo. En nuestra opinión, la segunda lectura es más tardía y crítica; prepara el propio concepto levinasiano de la intencionalidad ética. Así, en Totalité et Infini, Levinas dice que "La tesis según la cual toda intencionalidad es o una representación o se funda en una representación, domina las Logische Untersuchungen y vuelve a aparecer como una obsesión en toda la obra ulterior de Husserl" (1961, p. 127). 
mismos, nuestra inherencia en el mundo" (Levinas, 1931, p. 99). Ideas I, en efecto, establece que los sentimientos son abarcados por la sensibilidad lato sensu; tienen su propia unidad genérica y una afinidad esencial con la sensibilidad stricto sensu, es decir, entendida como "residuo fenomenológico de lo que procuran los 'sentidos' en la percepción exterior normal” (Husserl, 1913, p. 193).

Volviendo de nuevo al primer Levinas, merece la pena señalar su definición de la fenomenología como el "estudio intuitivo de la intencionalidad" (1929, p. 77) gracias al cual Husserl supera el psicologismo, que entiende la psique como un cajón en el que se depositan "objetos" psíquicos. La crítica que Husserl hace de él no es meramente gnoseológica (Levinas, 1930, p. 17), sino también ontológica, dado que rechaza la ontología propia del psicologismo que es el naturalismo, o sea, la concepción del ser como materia inerte, y le opone su propia ontología de la conciencia, cuya existencia está enraizada en la naturaleza pero, además, da razón de ella. Demuestra que el origen de todo ser, incluido el natural, está determinado por el sentido de la vida consciente y no a la inversa. Sus descripciones intuitivas de la conciencia ya no serán, por consiguiente, puramente psicológicas, porque "el mundo de las res trascendentes depende necesariamente de la conciencia" (Husserl, 1913, p. 104). La intencionalidad husserliana de la conciencia no tiene, como en Brentano, una trascendencia meramente psicológica, sino verdaderamente real.

Entendida como ciencia de la conciencia intencional, la fenomenología aborda la vida de esta sin reducirla a la simple imagen de una cosa, aprehendiéndola como su modo de existencia. Esto es lo que realmente le interesa al joven Levinas que mantiene siempre unidas la intencionalidad y la intuición para destacar tanto la apertura de la conciencia como la contribución de la cosa hacia la que la conciencia se dirige para ampliar la intuición. De ahí que vea en la intencionalidad la inauguración de una nueva ontología en la que el ser no solo es correlato de un pensamiento, sino que lo funda o lo constituye. Por eso dice Levinas que "la gran originalidad de M. Husserl consiste en ver que 'la relación con el objeto' no es algo que se intercale entre la conciencia y el objeto, sino que 'la relación con el objeto' es la conciencia misma" (1929, p. 62), su intencionalidad. El 
fenómeno originario es, por tanto, la relación. La distinción sujetoobjeto es posterior y, además, Husserl no los considera sustancias, sino polos de la intencionalidad. Por eso, dice Levinas que "la relación de intencionalidad no tiene nada de las relaciones entre objetos reales. Es esencialmente el acto de prestar sentido (la Sinngebung)" (1949, p. 32). El objeto no se aprehende descarnado, sino como un momento del fenómeno del sentido.

La lucha husserliana contra el naturalismo empobrecedor y a favor de la riqueza de la Lebenswelt, el mundo perdido de nuestra vida concreta, le revelará la actualidad de la fenomenología, hasta el punto de que "para los jóvenes alemanes que yo he conocido en Friburgo, esta nueva filosofía es más que una nueva teoría, es un nuevo ideal de vida, una nueva página de la historia, casi una nueva religión” (Levinas, 1931, p. 103), ya que inaugura un estilo de filosofar que da acceso a las potencialidades implicadas en las actualidades, "a una nueva posibilidad de pasar de una idea a otra, junto a la deducción, junto a la inducción y la dialéctica, a una nueva manera de desarrollar los 'conceptos', más allá de la apelación bergsoniana a la inspiración en la 'intuición”' (Levinas, 1996, pp. 76-77).

Ese "más allá" es, sin duda alguna, la intencionalidad, la condición de posibilidad de toda experiencia, que no es un sentimiento subjetivo que acompañe a los fenómenos psíquicos, sino "una intencionalidad en la que el objeto está en persona, ante la conciencia" (Levinas, 1930, p. 114). Las ciencias de hechos no dan cuenta de la evidencia ni explican cómo es posible la experiencia; son ajenas a la dignificación del espíritu y no pueden ofrecer una verdad esencial, pues carecen de la radicalidad fenomenológica. Por eso, Husserl consideraba a la fenomenología como la crítica última de cada ciencia particular y como "la determinación última del sentido del ser (die Letzte Sinnesbestimmung des 'Seins')” (Husserl, 1913, p. 133).

\section{Lectura de la reducción trascendental en Ideas I}

El joven Levinas comprendió que la intencionalidad fenomenológica no era una sustancia y que lo que se daba en ella no era el "yo pienso", sino el "ego cogito cogitatum", es decir, una correlación que no estaba contenida en la conciencia y que permitía 
distinguir la subjetividad en cuanto objeto mundano de la subjetividad trascendental dirigida a él. Gracias a esta última, tomamos conciencia de que "el ser no es otra cosa que el correlato de nuestra vida intuitiva” (Levinas, 1930, p. 138). Así se resume la superación fenomenólogica de la metafísica, consistente en no dar por supuesta ni la existencia ni la trascendencia del objeto; el sentido de ambas se constituye, siguiendo a Husserl, gracias a la inmanencia en la trascendencia de la subjetividad trascendental, que en el fondo es intersubjetividad trascendental. Esta constitución no significa que los fenómenos subjetivos sean constructos, ya que, como estamos viendo, no se dan separados del objeto que anuncian. ${ }^{4} \mathrm{El}$ ser trascendente es primeramente sujeto de las determinaciones sensibles, y solo por ellas es sujeto de las determinaciones físicas, que ya se anuncian en las sensibles. Se sigue de ello que "trascendente", en Husserl, es todo lo que no forma parte constitutiva de la corriente de la conciencia, "ante todo, el objeto material" (Levinas, 1930, p. 46, nota 25). A diferencia del idealismo de Berkeley, el idealismo trascendental de Husserl, por el que se siente atraído Levinas, no identifica el ser con el ser percibido, y ni siquiera comprende la intuición de la esencia como aprehensión de un en-sí independiente de su vivencia intencional. No es, por tanto, la apodicticidad de la esfera inmanente la que justifica la reducción fenomenológica, sino la apertura de la intencionalidad hacia el objeto y la apelación de este a la conciencia. ¿Significa esto que Levinas abraza la reducción trascendental de Ideas I?

En primer lugar, el filósofo lituano distingue con claridad la reducción de la epojé (puesta entre paréntesis de la existencia). La existencia de lo trascendente es, para Husserl, puramente fenoménica; en otras palabras, el modo de darse de la cosa no lleva asociada su existencia: "El sentido de existencia -esta noción tan general como vacía para la actitud ingenua que la presupone- se convierte en el objeto principal de la investigación fenomenólogica y debe ser explicitado por la fenomenología de la razón” (Levinas, 1929, p. 89). La modificación que pone entre paréntesis la tesis general de la

4 "L'apparition de la chose matérielle à travers une multiplicité d'Abschattungen-remarquons-le expressément- est inhérente à l'essence même de la chose" (Levinas, 1930, p. 25). 
existencia tiene como meta, según este filósofo, volver luego a ella con más radicalidad gracias a la razón que la libera de la estrechez del objeto natural y abre un campo trascendental.

En realidad, Husserl no hace referencia a la existencia o inexistencia, sino al modo de existir de las cosas. Pone entre paréntesis la tesis de existencia del mundo fundándose en su relatividad y en el relativismo de nuestro conocimiento de él, debido a que la evidencia de su realidad no está clausurada, dado que siempre hay anticipaciones y, por tanto, el modo de existencia del mundo nunca garantiza su existir. En cambio, la manera de existir de la conciencia es la evidencia. De ahí que el reconocimiento de la cosa en una serie infinita de escorzos sea precisamente la afirmación de su trascendencia, es decir, la distinción de la concordancia de sus apariciones, las cuales son todo lo que puede llegar a ser objeto de intuición. Ellas componen el ser de nuestra vida concreta, aunque nunca agotan la objetividad de la realidad, porque "objetividad" no es solo concordancia de actos intuitivos de un ego. En Ideas I, Husserl no desarrolla todavía la fenomenología de la intersubjetividad que sería necesaria para alcanzarla, pero su discípulo la estudió con detenimiento siguiendo sus cursos en Friburgo ${ }^{5}$ y en correspondencia con la objetividad, como una ilustración de la superación de la conciencia formal del neokantismo y como una transición hacia la relación ética con la alteridad. ${ }^{6}$

Como Husserl, Levinas reconoce que solo podemos vivir en el mundo como conciencias, y eso es posible por la epojé, que nos permite distanciarnos de la existencia para pensarla y decirla. La libertad de ejercerla da acceso a una vida reconducida que, en Husserl, no es una actitud provisional, pues permite alcanzar la fuente de todo ser, la vida íntegra "en la que se da el campo infinito

5 Afirma haber seguido en 1928 los cursos de Husserl sobre Psicología fenomenológica y, "en el invierno de 1928-9, los cursos sobre la constitución de la intersubjetividad" (Levinas, 1981, p. 29).

6 Levinas critica los estudios de Husserl sobre la intersubjetividad por considerar que suplantan la experiencia de alteridad del otro ego y lo convierten en un duplicado del propio. Le reprocha que aborde la alteridad como un dato reflexivo para la conciencia teórica, como un producto del poder constitutivo de la egología pura. Me permito citar sobre este asunto mi trabajo de 2001. Recientemente, S. Overgaard (2003) ha mostrado que la intersubjetividad fenomenológica no es mera presentación del otro como duplicado perceptivo del yo, sino, justamente, preservación de esa alteridad que Levinas reivindica. 
de las vivencias absolutas -el campo fundamental de la fenomenología" (Husserl, 1913, p. 107). Da la impresión de que Levinas haya quedado seducido por la actitud fenomenológica y por la reducción que le sigue y que, en palabras de Husserl, hace de la fenomenología "una disciplina puramente descriptiva que investiga el campo (Feld) de la conciencia pura trascendental en la intuición pura" (1913, p. 127). De ahí su independencia de cualquier otra disciplina. Reparemos en que la conciencia husserliana es "campo" y en que la fenomenología no es un constructivismo que se atrinchere en ella, sino su descripción. La suspensión de la actitud natural y la consiguiente reducción a la conciencia trascendental abren un campo de experiencia más radical que el de la visión ingenua de las cosas, dejando aparecer la realidad en su estructura última.

A pesar de que Levinas parece haberla comprendido así, ya en 1930 recusa la reducción husserliana entendida solo como un acto teórico (p. 203) con el que se reflexiona "sub specie aeternitatis" y se acaba intelectualizando la intuición. En cambio, la intuición bergsoniana no se desprende de la vida concreta, aunque implique cierta "reducción" de las cosas sub specie durationis. Esta última es el fundamento metafísico que necesitaría la fenomenología de Husserl (Levinas, 1930, p. 219). A pesar de que esta reducción no suprime nada de la trascendencia externa y de que, como Husserl declara, es el método por el que volvemos al hombre concreto, al campo de la conciencia pura en el que podemos practicar la intuición filosófica y superar el naturalismo (1913, p. 5), Levinas continúa creyendo que la reducción detiene el carácter operante del pensamiento, que es previo al pensamiento de los objetos.

Diecinueve años después, sigue insistiendo en la necesidad de la reducción, porque la reflexión no basta, ya que no suspende el compromiso con el mundo y no establece un punto de identificación de la multiplicidad de intenciones. Es precisa una actividad espiritual que no presuponga al mundo como su condición, una suspensión del sujeto empírico para reencontrarlo como filósofo. Eso es lo que efectúa la reducción, entendida ahora como "una violencia que se hace el hombre -ser entre otros seres- para reencontrarse como pensamiento puro" (Levinas, 1949, p. 52). Esta "violencia" que marca la diferencia ontológica proviene de la ruptura con la actitud ingenua, 
que identifica el mundo con el ser, y es una exigencia para recrear la pregunta filosófica que surge del distanciamiento provisional de lo dado por sentado para encontrar todo su sentido.

Así pues, la reducción fenomenológica no elimina nada, sino que reconduce lo mundano a la conciencia para comprender cómo es posible tanto la aparición de múltiples mundos relativos a ella como la del mundo común de la racionalidad. Así lo establece Husserl en el $\S 49$ de Ideas I, donde afirma que todo lo trascendente tiene una existencia relativa, mientras que la conciencia trascendental existe absoluta y necesariamente; tanto es así que sobreviviría a una "aniquilación del mundo" (Weltvernichtung) (Husserl, 1913, p. 103). Dicha aniquilación es un experimento; además, solo tiene explicación para la fenomenología estática desarrollada en esta obra, esa para la que el ser inmanente a la conciencia la convierte en absoluta, mientras que el ser trascendente siempre es relativo a ella. La existencia del mundo es concebida como correlato de la conciencia; su ser "por principio solo es susceptible de intuición y determinación en cuanto que es algo idéntico de multiplicidades motivadas de apariciones -pero que además de eso no es nada" (1913, p. 106). Así pues, la reducción nos lleva a la conciencia pura, a su vida trascendental, bien distinta de la trascendencia del objeto, que no es un producto suyo. La trascendencia de la existencia del mundo no es tampoco deducible de las categorías que constituyen su esencia, sino que consiste en el hecho de ser reencontrada por la conciencia o en ser, como decíamos, existencia con sentido.

Levinas valora positivamente esta remisión de toda existencia al modo de existir de la conciencia, a su intencionalidad, sin perder por ello su diferencia. Por ella, la existencia sabe de sí y la conciencia fenomenológica se desmarca de la conciencia natural. Esta última no es abandonada por Husserl; únicamente subraya que se constituye en la trascendental que, aunque no forma parte de la naturaleza, no es una abstracción, sino "el sujeto de todo acto y vive (lebt) en él 'actualmente"” (Husserl, 1913, p. 178). Es un yo "puro" porque nada lo compone; es en sí y por sí. A diferencia del yo empírico, no es un existente, sino una modalidad de ser. Con él, la fenomenología ha descubierto un nuevo dominio: el de lo subjetivo más objetivo que toda objetividad. En Meditaciones cartesianas, Husserl añadirá que 
por el método de la reducción trascendental cada uno de nosotros es llevado a su polo-ego, con su respectivo contenido (Gehalt) concretomonádico, como este ego fáctico, el único ego absoluto (1931, p. 103). No se pierde, por tanto, la singularidad de la persona, sino que se gana reflexión sobre la misma, pues el ego trascendental no es un principio formal, sino la configuración temporal de cada conciencia individual.

En el contexto de la fundación de la fenomenología trascendental como una ciencia de esencias, la reducción eidética resultaba imprescindible para alcanzar una universalidad esencial, no fáctica; la reducción trascendental, por su parte, purifica la vida concreta de toda interpretación naturalista; Levinas añade que "también es una toma de conciencia del hecho de que el origen del ser está en la vida concreta de la conciencia" (1930, p. 140), en la intencionalidad que abre a la trascendencia del objeto y, al mismo tiempo, la atraviesa. Este es el objetivo de la reconducción husserliana al yo puro y necesario -en el sentido de que no es una vivencia más, sino su fuente- al yo idéntico "diverso por principio para cada corriente de vivencias" (Husserl, 1913, p. 124), ${ }^{7}$ con el que se nos presenta "una trascendencia singular -no constituida-, una trascendencia en la inmanencia" (Husserl, 1913, p. 124). El filósofo lituano la interpreta como una "presencia de sí a sí que se despierta de su identidad de estado y se presenta a un yo (moi)" (Levinas, 1974, p. 46). Este es su modo de afirmar la trascendencia específica de la subjetividad sin recurrir a la inmanencia de lo Mismo.

En su juventud, el prototipo de toda trascendencia y el verdadero acto de trascendencia era la intencionalidad fenomenológica (1930, p. 69). Había que estudiarla porque tanto en ella como en el carácter consciente de las vivencias se expresaba la existencia. Dicho carácter inmanente a la conciencia de todo lo que la trasciende inclina a Levinas a declarar que la reducción "es una neutralización de nuestra vida para dirigir la mirada a ella” (1930, p. 222). Años después, irá más allá de esta concepción todavía procedimental para alcanzar la certeza y definirá la reducción como una "revolución interior", como "una manera de existir el espíritu conforme a su vocación y, en suma, a su ser libre en relación con el mundo" (1949, p. 54). En

7 En nota a la página de esta cita, Husserl reconoce que su concepción del yo puro es difícil y que, para clarificarla, le dedicará un capítulo en Ideas II en la que está trabajando ya por esos años (cfr. Husserl, 1952, pp. 97-120). 
efecto, la conciencia es absoluta porque existe como evidencia en la libertad, sin las ataduras de lo relativo. Ahora bien, el filósofo lituano dictamina que la única libertad que Husserl reconoce es la de neutralizar la tesis de existencia de la actitud natural para tematizarla, eso que su seguidor considera como "la libertad de la teoría" (Levinas, 1931, p. 222).

No le cabe duda de que uno de los grandes méritos de Husserl fue la reconducción de todas las tematizaciones a su fuente trascendental, pero echa en falta una mayor elucidación del sentido de la existencia absoluta de la conciencia. En nuestra opinión, Husserl lo ha clarificado al distinguirla de la reflexión, diciendo que la conciencia no solo es conciencia de algo y que no existe como tal cuando se la toma como objeto de una conciencia refleja, sino que ya antes de cualquier reflexión está ahí como fondo (Hintergrund), "lista para ser percibida (Wahrnehmungsbereit)" (Husserl, 1913, p. 95). ${ }^{8}$ Los objetos exteriores lo son de la conciencia; en cambio, su propia perceptibilidad es su modo de existir de modo absoluto, entendiendo por tal no solo su indubitabilidad, sino también su autorresponsabilidad, puesto que la conciencia existe llevando en sí la garantía de su existencia como lugar en el que se constituye todo ser.

Ideas I permanece en el nivel de la fenomenología estática y, por consiguiente, omite la conciencia interna del tiempo. Debido a ello, la reducción a la subjetividad trascendental permanece incompleta. Será preciso descubrir su significado en su constitución en el flujo temporal; entonces, se pondrá de manifiesto que la conciencia no solo es conciencia constituyente.

\section{Acerca de la necesidad de una reducción a la génesis}

Es preciso tener en cuenta que, a diferencia de la fenomenología estática que domina Ideas I, la fenomenología genética aborda la intencionalidad horizóntica y la genealogía de la conciencia, la pasividad de las habitualidades y, en suma, la presencia inobjetiva del sentido sedimentado. En esta fenomenología Husserl ya no pretende elaborar una ciencia de esencias, sino de asociaciones pasivas y sedimentaciones. Desde nuestra perspectiva, cuando en

8 Me permito remitir al lector interesado en esta temática a mi trabajo de 2017. 
Ideas I declara que "la corriente del ser fenomenológico tiene una capa material y otra noética [der Strom des phänomenologischen Seins hat eine stoffliche und eine noetische Schicht]" (1913, p. 196) parece ya estar anunciándola, pues distingue un nivel de análisis fenomenológicohilético y otro fenomenológico-noético, aunque juzga a este más importante y rico.

El predominio de esta capa es un rasgo de la ontología de Husserl que gira en torno al ser absoluto de la conciencia y a sus actos teoréticos que actualizan la existencia. Levinas concede, no obstante, que en Ideas I dio un paso adelante al afirmar que los actos no-teoréticos (valorar, desear, querer) también eran vivencias intencionales que constituían objetos con otro modo de verdad, porque la verdad fenomenológica no solo se halla en el juicio, sino primariamente en la evidencia intuitiva. En palabras de Husserl, estos actos no-teoréticos son "fuentes necesarias de diversas regiones del ser y, por lo tanto, de las ontologías correspondientes. Por ejemplo, la conciencia valorativa constituye la objetividad 'axiológica', que es nueva frente al mero mundo de las cosas" (1913, p. 272). Esto implica que la vida práctica y la estética poseen una intencionalidad afectica y axiológica, saludada por Levinas como "el magnífico descubrimiento hecho por Husserl" (1987, p. 214). Sin ella, toda vivencia que no estuviera dirigida al conocimiento quedaría reducida a mero contenido hilético; mientras que, por ella, puede haber, además, posicionamiento. Ahora bien, el filósofo lituano se pregunta si la posición como yo trascendental que asegura la verdad del ser en el aparecer no estará supeditada a una Urdoxa que no se pone en cuestión, a una síntesis sin síntesis o "a la trama ética anterior al conocimiento" (Levinas, 1987, p. 215). Esta anterioridad sin posicionamiento nos parece, cuando menos, discutible, pues la deliberación y la decisión ética ya hacen uso de un saber práctico.

En cualquier caso, el interés creciente de Levinas por esta trama lo llevará a la fenomenología genética, a la pasividad que permite comprender la subjetividad afectivamente sujeta al Otro. Este nuevo "sujeto" elude la ubicuidad constitutiva y la intencionalidad teorética, aunque, finalmente, la conciencia pasivamente afectada también es conciencia refleja que descarta lo vivido no intencional o simplemente lo sitúa en la conciencia pre-reflexiva. Levinas no acepta que esta 
sea solo una conciencia confusa; la considera, más bien, conciencia implícita que precede a cualquier intención como una eliminación (effacement) o como discreción de la presencia (1991, p. 147), porque no es un acto, no es voluntaria, ni siquiera descriptible como toma de conciencia de su pasividad; tal vez únicamente como afección del yo por el Otro. La conciencia pre-reflexiva no es una segunda conciencia, en efecto, sino una pasividad absoluta de la conciencia, una pasividad no asumida, ya que está del lado de la alteridad, muy cerca de la impresión originaria (Urimpression) husserliana.

Frente a esta concepción de la conciencia pre-reflexiva. MerleauPonty desarrollará la intencionalidad operante (fungierende), no yóica, pero viviente y determinante de la actividad del yo. En relación con ella, se desarrolla una pasividad que no es pura, sino actuante como todo lo que queda sedimentado. Esta concepción de la intencionalidad que va más allá de la oposición tradicional entre la actividad y la pasividad no le pasa desapercibida a Levinas que la descifra como una evidencia operante u obrante (1949, p. 36). A través de la intencionalidad "la fenomenología anuncia una metafísica de lo trascendental” (1949, p. 191) donde la relación con la alteridad no se fija polarizándola como una relación sujetoobjeto; más bien resulta necesaria otra intencionalidad distinta de la objetivante, una intencionalidad que remita a un horizonte trascendental y que Levinas descubre en los análisis husserlianos del cuerpo vivido (Leib) como horizonte de la sensación, del movimiento y de la libertad. La fenomenología genética reactiva los horizontes internos y externos forzando al pensamiento a salir de sí, ya que la intencionalidad lleva los pensamientos a los horizontes noemáticos en los que se sostiene el sujeto siempre dirigido al objeto. Dichos horizontes juegan un papel trascendental, porque no son vagos contextos, sino que forman parte de la propia situación del sujeto. Con frecuencia, se hallan escondidos y, por ello, no son descubiertos por los actos representativos de la conciencia. Se requiere un segundo acto, porque estos horizontes se abren "alrededor de 'intenciones' primeras", intenciones operantes en la trama humana e interhumana "que es la concretización de su impensado" (Levinas, 1983, p. 28). En nuestra opinión, ese "segundo acto" ha sido preparado por el paso de la actitud natural a la fenomenológica y por la reducción tal y como 
es entendida por Levinas, es decir, como esa operación que deja aparecer en el fenómeno "todas las dimensiones de sentido -todos los 'horizontes' que escapan de la ingenuidad de un pensamiendo que olvida reflexionar sobre sus propios desarrollos" (1987, p. 210).

Como vimos, el joven Levinas ya comprendía la intencionalidad como una manera de experimentar o vivir las relaciones intencionales, muy diferente de la dirigida a objetos, como una intencionalidad que no era intelección, sino, ante todo, conciencia interna del fluir. Esto que resulta fundamental para la fenomenología de la génesis, determina otra interpretación de la reducción distinta de la contenida en Ideas I y, en general, de la explicitada por la fenomenología estática, ya que la reducción a la subjetividad trascendental no es suficiente para dar cuenta de la génesis temporal. A lo sumo, la fenomenología estática descubre la subjetividad trascendental como fundamento y, tal vez, como auto-constituyente, puesto que su vuelta sobre sí no es mera introspección, sino que contribuye a la realización de la subjetividad trascendental misma.

En lugar de esta intencionalidad fundada en esta subjetividad trascendental, Levinas acepta una intencionalidad sin tematización encaminada a una "dación de sentido (Sinngebung) ética, es decir, esencialmente respetuosa del Otro" (1949, p. 188). Décadas después propone la noción de "contra-intencionalidad" por la que el privilegio constituyente recae en la llamada del Otro, cuya afectación origina la subjetividad y convierte al sujeto en su respuesta. Aunque no sea el acto de una conciencia constituyente, esta intencionalidad proporciona también un sentido, en su doble acepción de significado y dirección; se opone, sin embargo, a la intencionalidad de acto en la que sigue predominando la potencia yóica y, por ello, el pensador lituano se concentra en la responsabilidad por lo verdaderamente humano, la cual debe volver a la interioridad de la conciencia nointencional, esa que está más allá de la dicotomía entre ser y no ser, la que es posibilidad de "preferir la injusticia sufrida a la injusticia cometida” (Levinas, 1991, p. 151).

Una preferencia como esta no es irracional; tampoco es fruto de una mera desapropiación procedimental del yo, sino de la responsabilidad como testimonio de lo inmemorial. De ella surge la relación ética que, en opinión de Levinas, ni es intencional ni se refiere a 
una experiencia previa. Así es como se aleja de las concepciones tradicionales de la ética que la consideran una efectuación de la Razón, entendida como facultad de lo universal. La verdad de la ética no comienza con ella, sino con el diálogo Yo-Tú que valora al otro ser humano. Esta verdad del valor no es la otra cara de la evidencia; ni siquiera es la verdad del des-ocultamiento, sino la del testimonio: la conciencia responsable del Otro. Puesto que dicha conciencia no es una conciencia que reflexiona sobre sí misma y sobre lo que la rodea, no es conciencia intencional de la representación, aunque sí podría considerarse una intencionalidad operante, previa a la misma. Esta adhesión levinasiana a otra modalidad de la intencionalidad explica que, hasta sus últimos días, el filósofo evoque la justificación fenomenológica de la verdad. ${ }^{9}$ Desde nuestra perspectiva, ella misma es afán de verdad, entendida como rectitud (Richtigkeit) que apela a la acción y a la transformación, porque la historia no puede tener la última palabra y el "yo puedo" en el que se centra la fenomenología genética ha de medirse en su comportamiento con los otros en medio del mundo, sacando lecciones de la historia a la vez que la reconfigura con sus experiencias y con su praxis.

El interés levinasiano por explicitar la fenomenología genética es compartido por Merleau-Ponty, y por ello, ambos estudian pormenorizadamente los análisis de Ideen II, sobre todo, la vinculación del movimiento con la percepción, de las sensaciones localizables con las cinestésicas. Son conscientes de que la sensibilidad juega un papel central en la constitución de los objetos en esta obra de Husserl; es una especie de intencionalidad operante apreciable en la direccionalidad de los sentidos y en la irreductibilidad del sentir al conocer. Siguiendo a Levinas, la fenomenología de la sensibilidad cinestésica ha liberado las intenciones que no son en absoluto objetivantes -sino operantes y horizónticas- para poder pensar una exterioridad que no es objetiva. En efecto, la función trascendental que denota la sensibilidad, para Husserl, abre otra intencionalidad

9 Cfr. Poirié (1987, p. 110). En relación con esto, discrepamos de la afirmación de que "Levinas considere la fenomenología como una exigencia radical de prueba, haciéndose así heredero de un proyecto de fundación apodíctico" (Dubost, 2006, p. 34. La cursiva es nuestra). El interés levinasiano por la fenomenología no es solo gnoseológico y formal, sino que la interpreta, como estamos viendo, como un testimonio de los contenidos y de los sentidos que vienen de la intuición y de la intencionalidad, no de la autoridad. 
anterior a la objetivante, pues lo sensible es dado antes de ser buscado. El análisis fenomenológico de la sensibilidad es utilizado por Levinas como un medio para mostrar que lo que se da en ella no es un rendimiento ontológico del yo, sino, a la vez, lo donador y lo donado. Así, la teoría husserliana de lo sensible restituye al acontecimiento impresivo su función trascendental; descubre en él un pensamiento intencional que es el tiempo mismo.

La conciencia constituyente se revela, entonces, no solo como pensamiento, sino como acontecimiento en el tiempo: no es una conciencia eterna opuestaa otra temporal, pero tampoco es meramente una conciencia temporal. El filósofo lituano tiene muy presente que la conciencia del tiempo es el tiempo de la conciencia, dado que lo que temporaliza es ya temporalizado. Por lo tanto, la conciencia es conciencia de objeto, pero también conciencia no-objetivante de sí misma; es decir, se vive -es vivencia (Erlebnis)- como su intención. Asimismo, la conciencia es un flujo temporal de un material sensual, es el sentir mismo de la sensación. Los elementos de dicho material son los datos hiléticos y se distinguen de las cualidades del objeto alcanzadas por la intención trascendente, dado que la presencia del objeto no es pensada como tal, sino que se apoya en la materialidad de las sensaciones. Levinas interpreta la reconducción husserliana de las mismas a una subjetividad absoluta como el modo de aprehender el flujo, que es el sentir mismo de la sensación. Comprendida en el marco de la fenomenología de la génesis, la reducción tendría como meta la aprehensión del sentir mismo en su dinamismo, pero ¿cómo es posible esto que aparentemente es una paradoja? ¿Cómo volver al sentir en su propio movimiento?

Mientras que Husserl distinguía el pensar de lo pensado en el nivel del pensamiento, en el nivel sensible diferenciaba el sentir de lo sentido; este no era una cualidad del objeto en respuesta a una intención de la conciencia; aquél, por su parte, en la sensación, era conciencia de lo sentido y coincidencia con él, e intencionalidad, por tanto. Ahora bien, lo peculiar de la intencionalidad de lo sensible es su cinestesia, es decir, el hecho de que los sentidos que se abren a lo sensible se mueven para explorarlo y sienten que lo hacen. La cinestesia no es una imagen motriz, sino una verdadera intencionalidad operante, porque la sensación es el mismo moverse. 
Este es el modo en el que el sentiente siente lo sentido. En suma, no es el sujeto, sino el movimiento el que constituye la intencionalidad del sentir o, mejor, el que cumple su transitividad.

Así pues, la intencionalidad levinasiana carece de sujeto; su fuente es el movimiento, la vida y sus constantes relaciones, hasta el punto de que, si es viviente, "la intencionalidad es la unión del alma y del cuerpo" (Levinas, 1949, p. 196); la intencionalidad es la corporalidad unida a la espiritualidad que abre a la radicalidad del otro. Admitir esa unión es poner la espiritualidad de la conciencia en el movimiento por el que ella desborda su interioridad, una tendencia opuesta a la que anima al bergsonismo que, en la línea del espiritualismo tradicional, "investiga el espíritu como liberado del cuerpo" (1949, p. 198). En cambio, el filósofo lituano entiende la encarnación como la transitividad por excelencia que hace posible cualquier acto. Rescata esta intencionalidad transitiva, mucho más original y originaria que la objetiva. ${ }^{10}$

Esta transitividad dinámica de la conciencia incorporada es otro rendimiento de la superación fenomenológica del realismo y del idealismo. A diferencia de la constitución del objeto por la conciencia y de la conceptuación de la trascendencia como aprehensión de los actos constituyentes, en la intencionalidad transitiva no hay coincidencia entre yo y otro. De su no coincidencia surge una diferencia que hace que la intencionalidad sea, en parte, pasiva, un ver a qué apunta la conciencia trascendiéndose: "El descubrimiento de la intencionalidad en la praxis, la emoción, la valorización en la que hemos observado la novedad de la fenomenología, sólo toma prestado su vigor metafísico de la intencionalidad transitiva de la encarnación" (Levinas, 1949, p. 197). De ahí que Levinas considere la fenomenología del cuerpo vivido y de las cinestesias como la intencionalidad por excelencia. Por las Empfindnisse (sensaciones dobles o sensaciones de sentirse sintiendo), la relación con el objeto

10 Sin esta intencionalidad transitiva, la filosofía contemporánea del arte sería incomprensible, porque no es ni una aproximación al ideal de lo Bello, ni uno de los ornamentos de nuestra vida, ni el testimonio de nuestro tiempo, ni el reflejo de la economía, sino "la relación última con el ser en una anticipación, practicamente imposible, de lo que ya no es el ser -esta obra no se concibe fuera de la idea radical de la intencionalidad" (Levinas, 1949, p. 199 Nota al pie). Las similitudes con la intencionalidad operante o motriz de Merleau-Ponty son evidentes (me permito remitir al lector interesado en ella a mi trabajo de 2017). 
se encarna, mientras que el mundo se constituye por referencia a un sujeto que se tiene que mover para dirigirse a él. La sensación cinestésica no es un contenido sentido que señale modificaciones, sino que toda ella es modal y libre. Así es como este continuador de la fenomenología pone de relieve las potencialidades espirituales de esta sensibilidad y la entiende como "'encarnación' del pensamiento" o como "condicionamiento de lo mental en el 'cuerpo propio"” (Levinas, 1987, p. 150).

La sensibilidad levinasiana, su intencionalidad transitiva, nos abre a la trascendencia, entendida como Otro. Merleau-Ponty, a nuestro modo de ver, va más allá -o más acá- en su apertura a todo lo que es susceptible de ser otro. A diferencia de la trascendencia levinasiana sin inmanencia, reafirma la trascendencia en la inmanencia del cuerpo vivido "que no es fuera sin ser dentro" (MerleauPonty, 1964, p. 97). ${ }^{11}$ En 1984, Levinas parece coincidir con él en que el residuo de la reducción no es ni la absoluta inmanencia ni la absoluta trascendencia, sino el nivel del movimiento de la carne, que pone en cuestión la reducción trascendental de la sensibilidad y arroja una constitución que siempre presupone lo constituido:

La textura del constituyente estaría cosida con hilos que también provienen de lo constituido, sin que esta proveniencia haya tenido que responder a una "dirección intencional". Estos hilos pertenecerían al material psíquico y, si lo podemos decir, a la carne misma del espíritu. Esto no sería aquí precisamente una metáfora: el "proceso" espiritual del pensamiento sería también, por ejemplo, en el sentido propio del término, progreso y movimiento de un cuerpo humano. (Levinas, 1987, p. 148)

Husserl reconocía ya ese "material" o tejido de las intencionalidades en los datos hiléticos, pero su continuador es más radical: "la sensibilidad marca el carácter subjetivo del sujeto, el mismo movimiento de repliegue hacia el punto de partida de toda acogida", hacia la impresión originaria (Urimpression) que es el instante presente y, en consecuencia, "la individuación del sujeto" (Levinas,

11 El cuerpo no es en Merleau-Ponty pura inmanencia opuesta a la transparencia absoluta de la conciencia, sino fenómeno de una dimensión interior que no se manifiesta más que indirectamente, de un sí mismo en el seno de la carne (chair). Por su parte, la conciencia -siempre encarnada- no se presenta en la inmanencia y como contraria a la trascendencia de los objetos: es conciencia perceptiva. 
1949, pp. 165-166), en la que se reúnen pasividad y actividad, pues la impresión originaria no es conciencia de, sino el nacimiento de toda conciencia y de todo ser. La retención husserliana la modifica enseguida y se pierde su instantaneidad. En cambio, Levinas retrocede hacia ella y así deja fuera de juego la reducción al ego trascendental. Esta es interpretada ahora por el filósofo lituano como un regreso de la experiencia orientada a la verdad a una impresión originaria a partir de la cual la verdad adquiere sentido. La verdad continúa revelándose a la conciencia, pero esta ya no es soberana; constituye al objeto, pero sabe de la existencia de un mundo prepredicativo, de la impresión originaria que no es constituida. Es más, el propio Husserl aseguraba que la conciencia no era nada sin la impresión (1996, p. 107). No obstante, a Levinas le parece que la determinación de la conciencia huserliana viene únicamente de la retención de las impresiones ${ }^{12}$ y hasta la impresión originaria está habitada por la conciencia intencional; él sostiene, por el contrario, que la impresión es la precedencia de lo real, una anticipación que es también conciencia, pero sin modificación.

Con base en esas consideraciones críticas, y a pesar de su valoración de la riqueza de las descripciones contenidas en Ideas II, el filósofo lituano concluye que la obra está en la misma línea de las anteriores de Husserl; concretamente, cree que la encarnación husserliana se funda en la apercepción mediante la cual, ya en Ideas I, conciliaba la conciencia absoluta constituyente del mundo psicofísico con la conciencia entendida como proceso real perteneciente a dicho mundo.

Esto se debe a que Husserl entiende la Apperzeption como reflexión de la conciencia que permite adoptar o bien una actitud psicológica, dirigida a los estados de la conciencia, o bien una actitud fenomenológica, dirigida a la conciencia pura; la vivencia de ésta gana con aquélla una referencia intencional al yo y al cuerpo propio; ${ }^{13}$ a su vez, gracias a la conciencia pura, la conciencia psicológica descubre su esencia: la intencionalidad hacia el mundo exterior e interior. Tal movimiento centrífugo y centrípeto caracteriza, según

12 "La conciencia es senescencia y búsqueda de un tiempo perdido" (Levinas, 1949, p. 156).

13 El cuerpo es "un trascendental que condiciona la subjetividad" (Levinas, 1984, p. 406). 
Levinas, al yo puro husserliano que es el sujeto de la conciencia trascendental constituyente, del que dirá en sus últimas obras que debería interpretarse, en realidad, como "fuera de sujeto: sin reflexión [hors sujet: soi]" (Levinas, 1987, p. 213). La reducción que lleva a él es un "despertar del espíritu" (1974, p. 43) y, por tanto, no tiene que ver con las modalidades del conocimiento del ser. Esta reducción nos lleva a la subjetividad vigilante que huye de la identidad y pone en cuestión la primacía del proceso teórico. Para ello hay que practicar una fenomenología que abra la reflexión a la alteridad. Levinas no la encuentra, como acabamos de ver, ni siquiera en la fenomenología del cuerpo vivido en la empatía.

Volviendo al fragmento de Levinas que hemos reproducido arriba, advertimos su referencia a la carne (chair), término clave de la nueva ontología de Merleau-Ponty. Sin embargo, pensamos que no aluden a lo mismo. Merleau-Ponty la ejemplifica con la sensación doble de las manos enlazadas para subrayar la reversibilidad potencial de la carne entre lo sensible y lo sentiente. Así se experimentan sensaciones táctiles y cinestesias sin mediación de razonamientos, lo que es interpretado por Merleau-Ponty como una transferencia estesiológica. En cambio, Levinas designa como carne "una coincidencia de dos pensamientos en el saber mutuo del uno por el otro" (1987, p. 152). Este saber percibe el apretón de manos en el acontecimiento de "la paz rompiendo la conciencia-apercepción”, gracias a la différence como proximidad del prójimo, dirigida por "la no-in-diferencia de la responsabilidad-por-el prójimo” (p. 152). Respecto a esta no indiferencia, plantea la diferencia ética, mucho más esencial para el ser humano que la ontológica, ya que el problema más acuciante no es el del ser, sino el del bien. En nuestra opinión, quedan sin explicitar los contenidos que den sentido (dirección y significado) al bien y, en general, a la vida que responde a tal pretensión ética.

\section{Conclusión: la irreductibilidad de la responsabilidad ética}

La experiencia vivida por Levinas determinará sus obras de madurez que, cada vez, insistirán más en la responsabilidad hacia el Otro y en la ética como filosofía primera, porque solo a partir de ella las abstracciones metafísicas adquieren significación y eficacia. Un 
ejemplo de ello es su trascendencia de la concepción fenomenológica de la subjetividad como polo de identificación y re(con)ducción. Después de nuestro estudio, diríamos que, para la ética levinasiana, la "subjetividad" es, principalmente, vulnerabilidad; no es ni constituyente ni constituida; tan solo susceptible de recibir sentido en la medida en que entra en relación con Otro, pues este siempre es previo al yo y a mí. Nos preguntamos si realmente este cambio es tan radical como parece, es decir, si adoptar este otro paradigma de subjetividad sin identificación no significará únicamente superponer otra subjetividad a la propia.

En cualquier caso, Levinas intenta evitar que la ética arranque de ella y, por eso, establece su punto de partida en el reconocimiento del Otro y en la conciencia sin reflexión del mismo. Se deshace asimismo de la intencionalidad de la representación, característica de los actos de la conciencia, para abrazar una intencionalidad radicalmente ética: la de la exposición a la vida que nos insta a actuar. ¿Qué puede separar a esta ética de la fenomenología, cuya principal tarea es encontrar el sentido de la racionalidad teórica y práctica para que todos los seres que participan de ella la ejerzan con responsabilidad?

Al final de su vida, el filósofo lituano sigue declarando que Husserl está en el origen de sus escritos, que le enseñó a buscar esos horizontes de sentido que se difuminan cuando el pensamiento se absorbe en lo pensado, y a ver "el gran principio del que todo depende" (Levinas, 1991, p. 141): que la fuente de lo pensado es el pensamiento que lo tematiza y determina la articulación de su aparecer. Ahora bien, a él le impresiona el drama del existir, cuyas circunstancias no se reducen a meros fondos o decorados (1991, p. 66). De ahí que el sentido de existir por el que se va decantando no sea el fenomenológico -ni siquiera el de la intencionalidad operante o viviente al que nos hemos referido-, sino el revelado gracias a un impulso (élan) que ni siquiera "se da", sino que se recibe de Otro. La dación fenomenológica deja su lugar a la recepción y a la escucha.

Como vimos, ya en los años 30 acusaba a la fenomenología estática de comprender la conciencia en su aspecto activo y olvidar que "la vida concreta -fuente de la existencia del mundo- no es puramente teoría, aunque esta tenga, en Husserl, una dignidad 
completamente especial” (Levinas, 1930, p. 75). Finalmente, Husserl fundaba los valores, las voliciones y la evidencia práctica en los actos dóxicos, vinculando así la existencia al conocimiento, y la esencia de las vivencias a la reflexión: "el método fenomenológico se mueve exclusivamente en los actos de reflexión” (Husserl, 1913, p. 162), es decir, la existencia de las vivencias consiste en que son conscientes. Cada yo las vive y puede reflexionar sobre ellas; para ello, es necesaria la reducción fenomenológica que reconduce lo vivido a la conciencia pura. Ella es el punto de partida de la constitución de la universalidad, pero no su meta, de la misma manera que la universalidad no es un modo de existencia en el que se haya extraviado la humanidad, sino que "separada del yo que la constituye y que ella no agota, es un modo abstracto de 'existencia”' (Levinas, 1949, p. 169). Esta es la razón por la que afirma que, aunque los fenomenólogos no cumplan la reducción trascendental según las reglas del arte definido por Husserl, "sin embargo, se sitúan en su terreno" (1949, p. 225), que es el de una experiencia más alumbradora que concluyente. Ahora bien, Levinas no comparte el privilegio que la reducción husserliana ha concedido al yo. Por el contrario, cree que su función debería ser despertarlo de su embotamiento, re-animar su vida perdida en el anonimato, en suma, mantenerla en vilo, porque la vida debe ser vivida y no controlada.

Esta vida vigilante es también la que sigue a la reducción intersubjetiva de Husserl, tras la cual, el yo se libera de sí y se despierta del sueño dogmático de la apercepción pura: "reducción como explosión del Otro en el Mismo, hacia el insomnio absoluto, es una categoría bajo la cual el sujeto pierde la consistencia atómica de la apercepción trascendental" (Levinas, 1974, p. 55).14 De esta des-nucleación del sujeto nace la responsabilidad por el Otro en el orden del Infinito, un Otro que no es ni tema ni interlocutor; me despierta para vigilar al prójimo, a la responsabilidad por él. Entonces me encuentro en la vigilia, que es "de otro modo que ser" ("autrement qu'être"); es la manera de ser de la conciencia, pero no en razón de su poder constituyente; la vigilancia es, más bien, "despertar en la vigilia"

14 Según el filósofo lituano, el insomnio es más vigilante que la lucidez de la evidencia donde reposa el Mismo, "et encoré et déjà - rêve dans son présent" (Levinas, 1974, p. 61). 
("réveil dans l'éveil"), no-indiferencia ante la persona ajena; vigilia es, en definitiva, "la relación ética con el prójimo" (Levinas, 1974, p. 60), una relación que está guiada por la razón en vilo, que es "el Mismo siempre despertándose de sî" (1974, p. 57), el trastorno del Mismo por el Otro. La ética lo exige y lo podemos entender como una epojé distinta de la fenomenológica, como la deposición de la soberanía del yo y como la vigilia que evita caer en la trampa de una reducción al Mismo.

La razón en la que piensa el filósofo lituano ya no es la de la ontología, la de la posibilidad del mundo, pero tampoco es la de un yo puro, ni la de la progresión del saber. Desde su perspectiva, la razón es la absoluta trascendencia de la alteridad. No acepta, por consiguiente, que "la resolución de los problemas de la razón en la esfera dóxica tenga que preceder a la de los problemas de la razón axiológica y práctica" (Husserl, 1913, p. 324). Sin embargo, tampoco rechaza su idealismo trascendental, puesto que representa el cumplimiento del telos histórico de la racionalidad, del movimiento intencional de elucidación en la intuición volviendo a los actos en los que se desvelan los objetos, pues el acceso al objeto, en fenomenología, forma parte de su ser, de la verdad. El sujeto trascendental es el responsable de esa tarea infinita, de esa tensión entre el ideal del conocimiento teórico y los medios humanos para alcanzarlo. La confianza husserliana en el progreso indefinido del conocimiento debería, quizás, ceder ante Levinas para tomar conciencia de las regresiones del saber, sin rendirse a los puros facta, aunque sin ignorarlos.

La fenomenología genética de Ideas II, parece aproximarse a la ética levinasiana cuando adopta la actitud personalista, opuesta a la teorética. Para el filósofo lituano como para el de Prossnitz, la "persona" es la subjetividad que ha dejado de ser formal. En relación con ella, aquél expresa su admiración por los análisis que Ideas II dedica a la empatía (Einfühlung), ${ }^{15}$ porque presentan el sentido como un "saber" que no se encuentra ni en el objeto ni se cumple en el sujeto; no obstante, todavía considera que Husserl no llega a superar la estructura cognitiva de esta y otras vivencias y piensa el sentimiento

15 Cfr. Husserl (1952, pp. 167-172 [traducción al castellano: 2013, pp. 108-213]). 
a partir del conocimiento de los valores (Levinas, 1987, p. 153). ${ }^{16}$ En cambio, la empatía levinasiana es experiencia de alteridad, no como adecuación del yo al otro, sino como pasividad y gratuidad.

Si Husserl funda la axiología y la práctica en el conocimiento, Levinas parte de la responsabilidad de la que nace incluso el lenguaje ${ }^{17}$ y cuyo origen es la apresentación husserliana que nunca alcanza cumplimiento intuitivo. Dicha responsabilidad va más allá de la experiencia, hacia la trascendencia por medio del amor a Otro. Esta responsabilidad es "utopía" (Levinas, 1991, p. 261) de lo humano como desinterés por su ser (des-inter-esse). Bergson aún pensaba la trascendencia separada del mundo humano y, por ello, su espiritualismo provocó tanta hostilidad. En cambio, en la fenomenología que atrae la atención de Levinas, como vimos, "la trascendencia se produce por la cinestesia en la que el pensamiento se supera, no reencontrando una realidad objetiva, sino cumpliendo un movimiento corporal" (Levinas, 1949, p. 196). ${ }^{18}$ Esto significa que la trascendencia ya no será inmanencia fallida.

Con el tiempo, le parecerá insuficiente esa inteligibilidad trascendente como dimensión negativa respecto a la inteligibilidad imperante (la de la inmanencia y la presencia). Reclamará, entonces, otra fenomenología destructora de la del conocimiento, como dice C. Moreno, una "transfenomenología" (2010, p. 154), ${ }^{19}$ que vaya más allá de la experiencia, a la trascendencia que nos saca del aislamiento del existir del existencialismo y niega que el ser humano sea un serpara-la-muerte, afirmándolo como ser para-los-otros, hasta el punto de ser "responsable del otro en tanto que es mortal" (Levinas, 1993, p. 54)..$^{20}$ Lo que me hace sujeto es precisamente esa responsabilidad.

16 Desde la óptica de Levinas, la empatía no es un conocimiento que conduzca a la existencia de un pensamiento fuera del mío, sino una relación social cuya clave no es la adecuación de lo percibido con lo real, sino la generosidad imposible de delimitar como significación de un sentimiento. El saber no es ni el sentido ni el fin de todo (Levinas, 1974 , p. 233).

17 Según Levinas, lo dicho no cuenta tanto como el decir; en suma, se interesa menos por el contenido informativo del lenguaje que por el hecho de que se dirija a un interlocutor.

18 Cfr. Husserl (1952, pp. 152-153 [traducción al castellano: 2013, pp. 191-193]).

19 El autor la denomina de este modo, porque el horizonte de la alteridad lleva más allá del fenómeno.

20 El sujeto se constituye contra-la-muerte. Es la apertura al otro la que provoca el constante aplazamiento de esta, constituye la subjetividad y abre a la trascendencia, 
Así resulta difícil mantener la intencionalidad como libertad de dación a la conciencia, porque la responsabilidad levinasiana es previa incluso a la libertad de comprometerse. ¿No permanecemos así en un nivel de formalidad que iguala todas las alteridades y en una responsabilidad vacía de compromisos que puede llevarnos a la inacción?

Esta investigación quiere ser, como la misma fenomenología, una invitación a pensar en ello. Ha mostrado que la reducción husserliana a la subjetividad trascendental es una tarea de responsabilidad por la racionalidad y que Levinas la reformula recuperándola como distancia necesaria del mundo para pensarlo; asimismo, abraza el idealismo fenomenológico como el constante proceso de ideación que es nuestra existencia, y, en suma, se adhiere a la fenomenología como una instigación a la trascendencia, como una intencionalidad hacia una alteridad que, a nuestro modo de ver, corre el riesgo de ser tan absoluta y pura como el ego transcendental. Hemos destacado que a esta apertura le falta contenido, pero también que la reactivación levinasiana de otra intencionalidad no objetivante, sino transitiva, dinámica y motora, anunciada ya en la fenomenología de la génesis, constituye una llamada al estudio de las potencialidades de este otro lado de esta corriente filosófica nuclear, cuya prosecución es necesaria para hacer justicia al fenómeno de la vida y de la razón $\mathbf{C}$

que es sociabilidad o relación de alteridad absoluta que solo da el rostro, siempre único frente al que sólo cabe infinita responsabilidad, no reciprocidad (cfr. Levinas, 1948, p. 75). El rostro es un fenómeno límite, pues se da antes de cualquier dación de sentido (Sinngebung), es pre-temático. 


\section{Referencias}

Husserl, E. (1913/1992). Ideen zu einer reinen Phänomenologie und phänomenologischen Philosophie. Erstes Buch. Allgemeine Einführung in die reine Phänomenologie. Nachwort (1930). Gesammelte Schriften Band 5. Hamburg: Meiner.

Husserl, E. (1931/1963). Cartesianische Meditationen. Husserliana I. Den Haag: Nijhoff.

Husserl, E. (1952). Ideen $z u$ einer reinen Phänomenologie und phanomenologischen Philosophie. Zweites Buch: Phänomenologische Untersuchen zur Konstitution. Husserliana IV. Den Haag: Nijhoff. (Traducción al castellano, A. Zirión [2013]. Ideas II. México: F. C. E.)

Husserl, E. (1996). Zur Phänomenologie des inneren Zeitbewusstsein (18931917). Husserliana X. Den Haag: Nijhoff.

Levinas, E. (1929). Sur les "Ideen" de M. E. Husserl. Revue Philosophique de la France et de l'étranger, 43, 230-265 (recogida en Levinas, E. [1994]. Les imprévus de l'histoire [pp. 45-94]. Paris: Fata Morgana.)

Levinas, E. (1930/2001). Théorie de l'intuition dans la phénoménologie de Husserl. Paris: Vrin.

Levinas, E. (1931/1994). Fribourg, Husserl et la phénoménologie. In Les imprévus de l'histoire (pp. 94-109). Saint-Clément de Rivière: Fata Morgana.

Levinas, E. (1948/1991). Le temps et l'autre. Paris: PUF.

Levinas, E. (1949/2001). En découvrant l'existence avec Husserl et Heidegger. Paris: Vrin.

Levinas, E. (1961/1994). Totalité et Infini. Paris: Le Livre de Poche.

Levinas, E. (1974/1986). De la conscience à la vielle. À partir de Husserl. In De Dieu qui vient à la idée (pp. 34-61). Paris: Vrin.

Levinas, E. (1981). Éthique et Infini. Paris: Fayard.

Levinas, E. (1983). Transcendance et intelligilité. Genéve: Labor et Fides.

Levinas, E. (1984). Difficile Liberté. Paris: A. Michel.

Levinas, E. (1986). De Dieu qui vient à la idée. Paris: Vrin.

Levinas, E. (1987). Hors sujet. Paris: Fata Morgana.

Levinas, E. (1991). Entre nous. Essais sur la penser-à-l'autre. Paris: Grasset.

Levinas, E. (1993). Dieu, la Mort et le Temps. Paris : Grasset.

Levinas, E. (1996). Emmanuel Levinas, essais et entretiens (avec F. Poirié). Paris: Actes Sud. 
López Sáenz, M.a C. (2001). El problema del otro en la filosofía de E. Levinas. Investigaciones Fenomenológicas, 3, 265-282. Disponible en https://bit.ly/2JDjU3y

López Sáenz, M.a C. (2017). Intencionalidad operante en la existencia. En B. Sylla, I. Borges y M. Casanova (Coords.), Fenomenologia Hoje VI. Intencionalidade e Cuidado (pp. 79-119). Rio de Janeiro: Via Verita.

López Sáenz, M.a C. (2017). La percepción reconducida a la esfera trascendental en Ideas I. Convivium, (27-28), 63-87. Disponible en https://bit.ly/2LQfVNC

Merleau-Ponty, M. (1964). Le Visible et l'Invisible. Paris: Gallimard.

Moreno, C. (2010). Fenomenología y filosofía existencial. Volumen II. Entusiasmos y disidencias. Madrid: Síntesis.

Overgaard, S. (2003). On Levinas "Critique of Husserl". In D. Zahavi, S. Heinämaa, \& H. Ruin (Eds), Metaphysics, Facticity, Interpretation (pp. 115-138). Dordrecht: Kluwer.

Pagés, C. (2010). "Distance et proximité": les deux lectures Levinassiennes de l'intentionnalité. Bulletin d'analyse phénoménologique, 6(8), 264 283. Disponible en https://bit.ly/2lawnNB

Poirié, F. (1987). Levinas, qui êtes-vous? Lyon: La Manufacture.

Schiffer, D. S. (2007). La filosofía de Emmanuel Levinas. Buenos Aires: Nueva Visión.

Viellard-Baron, J.-L. (2010). Levinas et Bergson. Revue Philosophique de la France et de l'étranger, 4, 455-478. Disponible en https://bit.ly/2JPz6tE 